\title{
Congenital Syphilis: A Case Report
}

\author{
Subedi $\mathbf{S}^{1}$, Jwarchan J', Pandit SR ${ }^{2}$, Neupane $\mathbf{S}^{3}$ \\ ${ }^{1}$ Lecturer, ${ }^{2}$ Resident, ${ }^{3}$ Professor, Department of Dermatology, Gandaki Medical College, Pokhara, Nepal
}

\begin{abstract}
Congenital syphilis is a chronic infectious disease caused by Treponema pallidum, a spirochete acquired in-utero by the fetus. Syphilis continues to affect pregnant population, in spite of various measures to control. Here we report a case of congenital syphilis in a two year old male child.
\end{abstract}

Key words: Penicillins; Spirochaetales; Syphilis, Congenital; Treponema pallidum

\section{Introduction:}

$\mathrm{C}$ ongenital syphilis is a chronic infectious disease caused by Treponema pallidum, a spirochete acquired in-utero by the fetus. ${ }^{1}$ Occasionally, it can be acquired through direct contact with infectious lesions in the birth canal or on the perineum of the mother during the birth process. ${ }^{2}$ Syphilis continues to affect pregnant population, in spite of various measures to control. ${ }^{3}$ Antenatal screening for syphilis is cost beneficial and cost effective and penicillin is effective and cheap, , still congenital syphilis remains an important cause of various systemic effects such as neurological, developmental and musculoskeletal disability and death in infants, especially in resource poor settings. ${ }^{4}$ The most common cutaneous finding of congenital syphilis is a symmetrical, coppery red maculopapular rashes whereas less commonly, various other eruptions may be present in the form of acral skin desquamation, acral vesiculobullae (pemphigus syphiliticus), mucous patches, petechiae, erythema multiforme-like targetoid lesions, perioral/perinasal/ perianal fissures, and condylomata lata. ${ }^{2}$

\section{Case report}

A two years old male child presented to Dermatology OPD of Gandaki Medical College Teaching Hospital, Pokhara with asymptomatic foul smelling raised

Financial disclosure: None.

Conflict of interest to disclosure: None declared.

Address of Correspondence

Dr. Saujan Subedi

Lecturer

Department of Dermatology, Gandaki Medical College, Pokhara, Nepal

E-mail: saujan.subedi2015@gmail.com lesion over perianal region since five months. The lesion started as small raised single lesion which gradually progressed to the present form over the given duration. Patient's mother gives no history of any form of trauma/injury to the site or sexual assault of the child. No history of diarrhea, abdominal pain and blood in stool. He was born by normal, uneventful vaginal delivery to non-consanguineous parents and had no developmental impairment.

On examination, he had single erythematous, cerebriform plaque measuring about $3 \times 4 \mathrm{~cm}$ in size over perianal region. The lesion was soft to firm and non-tender on palpation (Figure 1). There were no other significant cutaneous lesions. Systemic examination was within normal limits. Our differential diagnoses were condyloma lata, cutaneous tuberculosis, cutaneous crohn's disease and perianal langerhans cell histiocytosis.

On investigation, venereal disease research laboratory (VDRL) was reactive (1:64) and TPHA was positive. Other tests like complete blood count, serum AST, ALT, creatinine were within normal limits, HIV, Hepatitis

Submitted: $12^{\text {th }}$ February 2020

Accepted: $27^{\text {th }}$ February 2020

Published: $7^{\text {th }}$ October 2020

How to cite this article

Subedi S, Jwarchan J, Pandit SR, Neupane S. Congenital Syphilis: A case report. Nepal Journal of Dermatology, Venereology and Leprology 2020;18(1):73-5. https://doi.org/10.3126/njdvl. v18i1.30315.

\section{(c) (i)}

Licensed under CC BY 4.0 International License which permits use, distribution and reproduction in any medium, provided the original work is properly cited. 
serology were negative and urine routine examination was normal. Mother's VDRL turned out to be reactive (1:8) and TPHA was positive.

From history, examination and blood investigations we made the diagnosis of congenital syphilis. But due to the unavailability of Benzathine Penicillinin in our region, we had to refer patient to other centre in Kathmandu. On follow up after the completion of treatment, the patient presented with healing lesion with decrease in size and thickness.

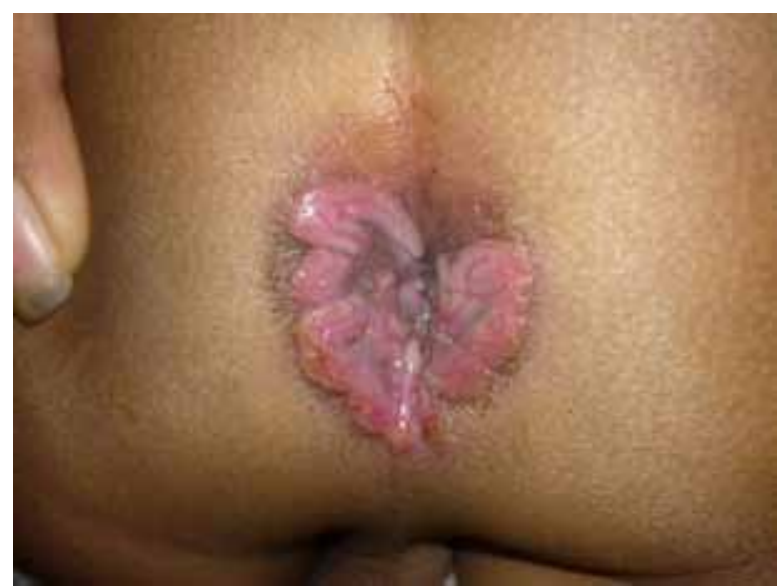

Figure 1: Erythematous, cerebriform plaque measuring about $3 \times 4 \mathrm{~cm}$ in size over perianal region.

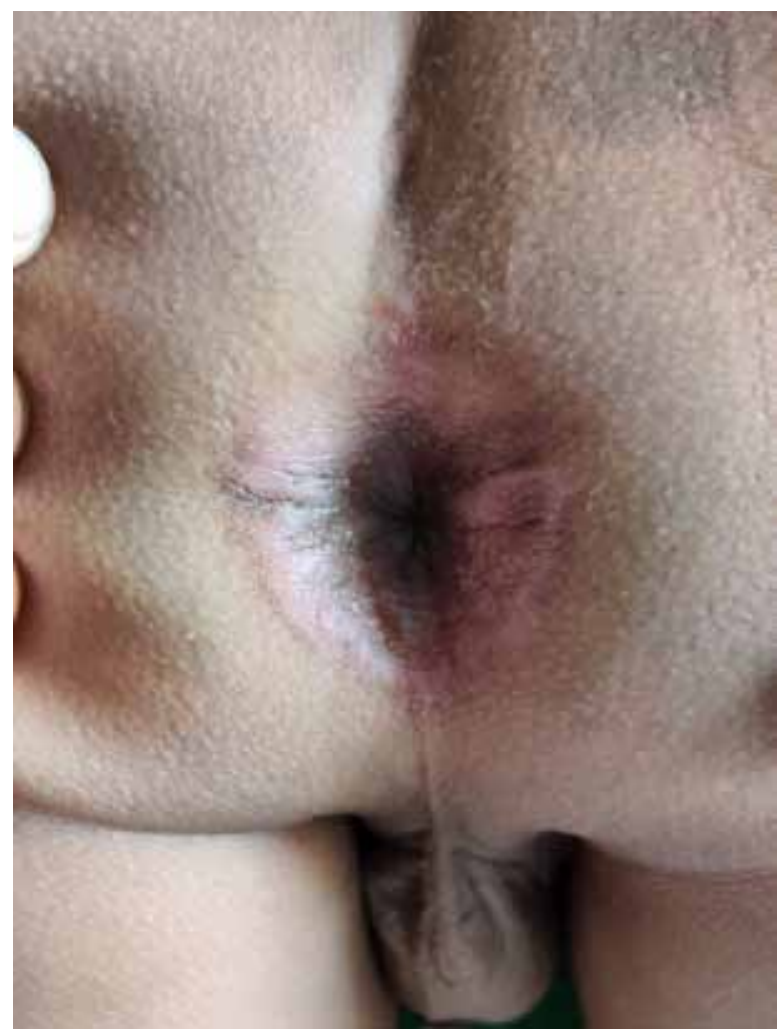

Figure 2: Post treatment photograph showing healing lesion with decrease in size and thickness

\section{Discussion}

Congenital syphilis is divided into early and late congenital syphilis. The early congenital syphilis has onset of clinical manifestations before two years of age while the late congenital syphilis has onset of clinical manifestations after two years of age (usually manifesting around puberty). ${ }^{2}$ It is a serious public health issue. Once believed to be a rare disease in developed countries, but recent data suggest that there is a surge in the incidence of congenital syphilis in North America and Europe. ${ }^{2}$

According to $\mathrm{WHO}$, new estimates published show that there were more than half a million (around 661,000) total cases of congenital syphilis in 2016, resulting in over 200,000 stillbirths and neonatal deaths. ${ }^{5}$ As per the report on global sexually transmitted infection surveillance, 2018, congenital syphilis rate (cases per 100,000 live births, median and range) as reported by 59 countries, by region, 2016-2017 in different WHO regions are: 48.9 (African region), 22.8 (Region of the Americas), 0.9 (Eastern Mediterranean region), 0.4 (European region), 0.9 (South-East Asia region), 5.2 (Western Pacific region) and 5.2 (Overall). ${ }^{6}$

According to National guidelines on case management of sexually transmitted infections, revision 2014, treatment of congenital syphilis is:

- Early congenital syphilis (<2years of age) with clinical CNS involvement or with abnormal CSF: Aqueous procaine penicillin, 50,000 IU/ kg, single daily dose IM for 10 days; and normal CSF: Benzathine penicillin 50,000IU/kg IM stat.

- $\quad$ Late congenital syphilis (>2years of age): Aqueous crystalline penicillin, 300,000 IU/ $\mathrm{kg}$, daily IM, in divided doses, for 10 days- not to exceed 1.2 million units daily.

- For penicillin allergic children after the first month of life: Erythromycin $10 \mathrm{mg} / \mathrm{kg}$, four times daily for 30 days. $^{7}$

In a study carried out by HRP, the Special Programme of Research, Development and Research Training in Human Reproduction in WHO's Department of Reproductive Health and Research and the Clinton Health Access Initiative (CHAI) over two years (20142016), of the 114 countries approached, 95 had evaluable information and out of these 95 countries, 39 (41\%) reported a Benzathine Penicillin G shortage, and 56 (59\%) reported no shortage. Ten of the 95 countries reported the use of alternative antibiotics including ceftriaxone, amoxicillin, and erythromycin. ${ }^{8}$ 


\section{Conclusion}

We are reporting this case because of rarity of the disease, and atypical presentation of the patient.

\section{References}

1. NORD (National Organization for Rare Disorders). Congenital Syphilis; 2020 [Internet]. [Accessed 9th February 2020]. Available from: https:// rarediseases.org/rare-diseases/congenitalsyphilis/

2. Leung AK, Leong K, Lam JM. A case of congenital syphilis presenting with unusual skin eruptions. Case reports in pediatrics. 2018;2018. https:// doi.org/10.1155/2018/1761454

3. Murali MV, Nirmala C, Rao JV. Symptomatic early congenital syphilis: a common but forgotten disease. Case reports in pediatrics. 2012;2012. https://doi.org/10.1155/2012/934634

4. Phiske MM. Current trends in congenital syphilis. Indian J Sex Transm Dis AIDS. 2014 Jan;35(1):12. https://doi.org/10.4103/0253-7184.132404

5. World Health Organization. WHO publishes new estimates on congenital syphilis [Internet]. World Health Organization; 2020. [Accessed 9th February2020]. Available from: https://www. who.int/reproductivehealth/congenital-syphilisestimates/en/
Mother to child transmission of the syphilis can be prevented if properly investigated and treated during antenatal visit. Benzathine Penicillin is very effective against syphilis. Hence, there should be easy availability of this drug in every corner.

6. World Health Organisation. Report on global sexually transmitted infection surveillance, 2018 [Internet]. Geneva: World Health Organization; 2018 [Accessed 9th February2020]. Available from: https://apps.who.int/iris/bitstream/ha ndle/10665/277258/9789241565691-eng. pdf?ua $=1$

7. National Centre for AIDS and STD Control. National Guidelines on Case Management of Sexually Transmitted Infections, 2014 [Internet]. National Centre for AIDS and STD Control (NCASC), Ministry of Health and Population, Kathmandu, Nepal, 2014. 73p [Accessed 9th February 2020]. Available from: https:// mohp.gov.np/downloads/National\%20STI\%20 Guidelines\%202014.pdf

8. World Health Organization. Shortages of benzathine penicillin. How big is the problem? And why it matters [Internet]; 2020 [Accessed 9th February 2020]. Available from: https:// www.who.int/reproductivehealth/shortagesbenzathine-penicillin/en/ 